\title{
Nasal vaccination with a proteosome-based adjuvant and glatiramer acetate clears $\beta$-amyloid in a mouse model of Alzheimer disease
}

\author{
Dan Frenkel, ${ }^{1}$ Ruth Maron, ${ }^{1}$ David S. Burt, ${ }^{2}$ and Howard L. Weiner ${ }^{1}$ \\ ${ }^{1}$ Center for Neurologic Diseases, Department of Neurology, Brigham and Women's Hospital, Harvard Medical School, Boston, \\ Massachusetts, USA. ${ }^{2}$ ID Biomedical Corporation of Quebec, Laval, Quebec, Canada.
}

\begin{abstract}
Amyloid $\beta$-peptide (A $\beta$ ) appears to play a key pathogenic role in Alzheimer disease (AD). Immune therapy in mouse models of $A D$ via $A \beta$ immunization or passive administration of $A \beta$ antibodies markedly reduces $A \beta$ levels and reverses behavioral impairment. However, a human trial of $A \beta$ immunization led to meningoencephalitis in some patients and was discontinued. Here we show that nasal vaccination with a proteosome-based adjuvant that is well tolerated in humans plus glatiramer acetate, an FDA-approved synthetic copolymer used to treat multiple sclerosis, potently decreases $\mathrm{A} \beta$ plaques in an AD mouse model. This effect did not require the presence of antibody, as it was observed in B cell-deficient (Ig $\mu-n u l l)$ mice. Vaccinated animals developed activated microglia that colocalized with $A \beta$ fibrils, and the extent of microglial activation correlated strongly with the decrease in $A \beta$ fibrils. Activation of microglia and clearing of $A \beta$ occurred with the adjuvant alone, although to a lesser degree. Our results identify a novel approach to immune therapy for $A D$ that involves clearing of $A \beta$ through the utilization of compounds that have been safely tested on or are currently in use in humans.
\end{abstract}

\section{Introduction}

Alzheimer disease (AD) is the most common form of senile dementia, affecting more than 18 million people worldwide. With increased life expectancy, this number is expected to rise in the future. $\mathrm{AD}$ is characterized by widespread functional disturbance of the human brain. The classical neuropathological features are senile plaques, neurofibrillary tangles composed of paired helical filaments, and dystrophic neuritis. Compact senile plaques composed of amyloid $\beta$-peptide (A $\beta$ ) fibrils are associated with pathological changes in the surrounding brain neurons that lead to their death. $\mathrm{A} \beta$ appears to play a key pathogenic role in $\mathrm{AD}(1)$, and studies have connected the $A \beta$ plaque with formation of intracellular tau tangles, another neurotoxic feature of $\operatorname{AD}(2,3)$.

A body of work has accumulated demonstrating that anti-A $\beta$ antibodies are effective in clearance of amyloid deposits in vitro and in amyloid precursor protein-Tg (APP-Tg) mice (4-10). Solomon et al. showed in vitro that anti-A $\beta$ antibodies can lead to disaggregation of $A \beta$ fibrils, restoring $A \beta$ solubility and thus prevent neurotoxic effects on cell lines $(11,12)$. Schenk et al. then demonstrated that parenteral immunization of APP-Tg mice with synthetic $A \beta$ in complete Freund adjuvant (CFA) markedly decreased the number and density of $A \beta$ deposits in the brain, with concomitant

Nonstandard abbreviations used: $A \beta$, amyloid $\beta$-peptide; $A D$, Alzheimer disease; APP, amyloid precursor protein; BBB, blood-brain barrier; CFA, complete Freund adjuvant; FcR, Fc receptor; GA, glatiramer acetate; GFAP, glial fibrillary acidic protein; MBP, myelin basic protein; M-CSFR, M-CSF receptor; MOG, myelin oligodendrocyte glycoprotein; PLP, myelin proteolipid protein; PT, pertussis toxin.

Conflict of interest: D.S. Burt is an employee of ID Biomedical Corporation of Quebec and has share options in the company.

Citation for this article: J. Clin. Invest. 115:2423-2433 (2005).

doi:10.1172/JCI23241. improvements in neuritic dystrophy and gliosis (4). We observed $\mathrm{A} \beta$ clearance after repetitive mucosal (intranasal) administration of $A \beta$ peptide to $\mathrm{Tg}$ mice (5). Subsequent studies demonstrated that clearance of $A \beta$ following immunization protected APP-Tg mice from developing memory deficits $(6,7)$. Clearance of $A \beta$ and improvement of memory were also observed after passive administration of antibodies against $A \beta(9,10)$.

The exact mechanism by which antibody reduces $A \beta$ deposition in animals is not known (13). Possible mechanisms include Fc receptor-mediated (FcR-mediated) phagocytosis via microglia (4, $9,14-16)$, dissolution of amyloid fibrils $(12,17)$, and sequestration of circulating $A \beta$ resulting in an increased net efflux of $A \beta$ from brain and plasma (10). The robust reduction in brain $A \beta$ burden in FcR-deficient, $\operatorname{Tg} 2576$ transgenic mice following A $\beta$ active immunization (18) suggests that alternative mechanisms besides FcRmediated clearance occur.

A human trial of $A \beta$ immunization led to meningoencephalitis in some patients and was discontinued $(19,20)$. Analysis of autopsy findings from an $\mathrm{AD}$ patient vaccinated parenterally with $\mathrm{A} \beta$ 1-42 in QS-21 adjuvant demonstrated meningoencephalitis, infiltration of the brain by macrophages, and also an apparent reduction in amyloid deposits in certain regions of the neocortex (20). Hock et al. (21) reported that patients with brain-reactive anti-A $\beta$ antibodies had a significantly slower rate of cognitive decline than those that did not have brain-reactive anti-A $\beta$ antibodies.

Based on the finding that some AD patients immunized with $\mathrm{A} \beta$ developed meningoencephalitis (19), which in some respects resembled EAE, we initiated experiments to determine whether $\mathrm{A} \beta$ producing mice were more susceptible to EAE than their non$\mathrm{Tg}$ littermates. During the course of investigating the induction of EAE in APP-Tg mice, we discovered that there was reduction 


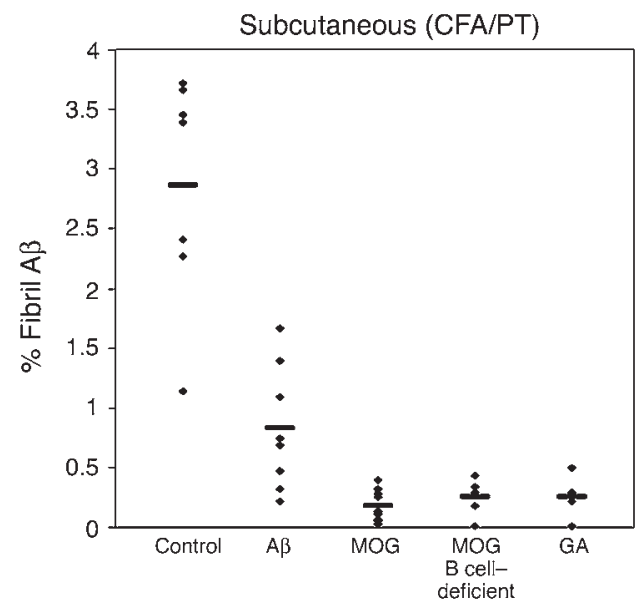

\section{Figure 1}

Effect of subcutaneous immunization on fibril $A \beta$ levels in the brain. To measure $A \beta$ fibrils, the left hemisphere of each mouse was cut into 14- $\mu \mathrm{m}$ longitudinal sections and stained with thioflavin S. Multiple sections from the identical regions were examined for each treatment group. The quantification was performed in a blinded fashion using Imaging Research software from the NIH. $P<0.01$, A $\beta$ versus control; $P<0.001$, MOG, MOG B cell-deficient, and GA versus control.

of $\beta$ amyloid in the brain that occurred independently of anti-A $\beta$ antibodies. These results led to experiments demonstrating that nasal vaccination with a proteosome-based adjuvant that is well tolerated in humans (22) plus glatiramer acetate (GA), an FDAapproved synthetic copolymer used to treat multiple sclerosis (23), potently decreases $\mathrm{A} \beta$ plaques in an $\mathrm{AD}$ mouse model.

\section{Results}

Induction of EAE in APP-Tg mice results in a decrease of $A \beta$ levels in the brain. Based on the finding that some $\mathrm{AD}$ patients immunized with $A \beta$ developed meningoencephalitis (19), which in some respects resembled EAE, we wished to determine whether $A \beta$-producing mice were more susceptible to EAE than their non-Tg littermates. We immunized aged APP-Tg mice with robust amyloid pathology (J20 mice) (24) with myelin oligodendrocyte glycoprotein (MOG) peptide 35-55 subcutaneously in CFA plus pertussis toxin (PT). As controls, APP-Tg mice were immunized with BSA or synthetic human $\mathrm{A} \beta$ 1-40. We found that EAE developed to an identical degree in APP-Tg animals and non-Tg littermates (data not shown), and no EAE was observed in APP-Tg mice immunized with $A \beta 1-40$ or BSA.

Unexpectedly, when we examined the brains neuropathologically, we discovered that there was markedly less $A \beta$ deposition in mice that had developed EAE. We quantified the amount of staining for $A \beta$ fibrils in the hippocampus using thioflavin $\mathrm{S}$ staining and found a $92 \%$ reduction in the MOG-immunized mice versus controls $(P<0.001)$ and a $73 \%$ reduction compared with mice immunized with $\mathrm{A} \beta 1-40(P=0.03$; Table 1 and Figure 1). We also quantified the total brain $\mathrm{A} \beta$ content by ELISA and found a $94 \%$ reduction in $\mathrm{A} \beta$ in MOG immunized animals compared with controls $(P<0.001)$ and an $86 \%$ reduction compared with $A \beta 1-40-$ immunized mice $(P=0.03$; Table 1 and Figure 1$)$. No changes were observed in animals immunized with BSA in CFA plus PT. We thus used untreated and BSA-treated animals as controls.

In order to determine whether the dramatic effect we observed was unique to MOG-induced EAE, we induced EAE with myelin proteolipid protein (PLP) peptide 139-151 in CFA plus PT. To induce EAE with PLP, we used aged APP-transgenic mice (Tg2576; average age 16 months) described by Hsiao et al. (25), which are on a B6/SJL background and thus susceptible to PLP-induced EAE. We found a $76 \%$ reduction of thioflavin $S$ staining for $A \beta$ fibrils $(P<0.002)$ and a $70 \%$ reduction in total brain $A \beta$ levels in animals with PLP-induced EAE $(P<0.02)$ versus controls (Table 2$)$. Our results with Tg2576 mice were similar to those obtained when we immunized J20 mice with MOG to induce EAE (Table 1). These results demonstrate that our observation was not related to either the antigen used for EAE induction or the animal model of AD studied.

$A \beta$ levels are reduced in B cell-deficient ( $I g \mu-$ null) mice with MOGinduced EAE. In previous studies involving mouse models of AD in which animals were immunized with $A \beta$ in CFA, anti-amyloid antibodies were shown to have a key role both in vitro $(11,12,17)$ and in vivo (4-9) in reducing amyloid load. We therefore measured levels of antibodies against $A \beta$ in mice immunized with MOG or PLP peptides to determine whether any humoral cross-reactivity to $A \beta$ had occurred. As shown in Tables 1 and 2 , we could not detect anti-A $\beta$ antibodies in animals immunized with MOG or PLP peptides. To definitively establish that antibodies were not playing a role in the EAE-induced clearance of $A \beta$, we immunized aged J20 mice bred to B cell-deficient mice with MOG 35-55 in CFA. As shown in Table 1 and Figure 1, B cell-deficient APP-Tg mice showed a more than $90 \%$ reduction in amyloid load compared with untreated mice, as measured by either thioflavin $\mathrm{S}$ staining $(P<0.001)$ or ELISA for total brain $\mathrm{A} \beta(P<0.001)$. These results establish that the reduction of $A \beta$ following MOG immunization occurs by an antibody-independent mechanism.

Clearance of $A \beta$ following immunization with $G A$. Because we were interested in the potential application of our findings to the treatment of $\mathrm{AD}$ in human subjects, we next addressed the question of whether we could immunize APP-Tg mice in a manner that would result in $A \beta$ clearance without causing EAE. To answer this

\section{Table 1}

Effect of subcutaneous immunization on total and fibrillar A $\beta$ in the brains of J20 APP-Tg mice

\begin{tabular}{lccccc}
$\begin{array}{c}\text { No. of mice } \\
\text { per group }\end{array}$ & $\begin{array}{c}\text { EAE } \\
\text { score }\end{array}$ & $\begin{array}{c}\text { Anti-A } \beta \\
\text { antibodyA }\end{array}$ & $\begin{array}{c}\text { Total brain } \\
\mathbf{A} \beta \text { (ng/g) }\end{array}$ & $\begin{array}{c}\text { \% Area of } \\
\text { thioflavin S-positive A } \beta \\
\text { plaques (hippocampus) }\end{array}$ \\
ControlB & 7 & 0 & 0 & $1,409.4 \pm 152.7$ & $2.9 \pm 0.4$ \\
A $\beta$ & 8 & 0 & 0.75 & $633.3 \pm 166.8^{\mathrm{C}}$ & $0.83 \pm 0.3^{\mathrm{C}}$ \\
MOG & 10 & $2.5 \pm 0.8$ & 0 & $87.7 \pm 19.2^{\mathrm{D}}$ & $0.22 \pm 0.1^{\mathrm{D}}$ \\
MOG B cell-deficient & 6 & $2.7 \pm 0.4$ & 0 & $118.8 \pm 25.2^{\mathrm{D}}$ & $0.27 \pm 0.04^{\mathrm{E}}$ \\
GA & 5 & 0 & 0 & $406.7 \pm 133.6^{\mathrm{E}}$ & $0.26 \pm 0.1^{\mathrm{E}}$ \\
\hline
\end{tabular}

${ }^{A}$ Results are presented as level of $\mathrm{OD}_{450}$ at a titer of 1:500 IgG. ${ }^{\mathrm{B} C o n t r o l}$ includes both untreated $(n=4)$ and BSA/CFA-treated $(n=3)$ animals, as there was no difference between these groups. Total brain A $\beta$ levels were: untreated, $1,528.75 \pm 288.125 \mathrm{ng} / \mathrm{g}$; BSA/CFA-treated, $1,290.5 \pm 345.8 \mathrm{ng} / \mathrm{g}$. The percent area of thioflavin S-positive $A \beta$ plaques was: untreated, $3.1 \% \pm 0.5 \%$; BSA/CFA-treated, $2.7 \% \pm 0.65 \%$. Statistical analysis was performed using 1-way ANOVA with Bonferroni correction. ${ }^{C} P<0.01$ versus control. ${ }^{D} P<0.001$ versus control; $P<0.05$ versus $A \beta$ E $P<0.001$ versus control. 
Table 2

Effect of PLP immunization on total and fibrillar A $\beta$ in the brains of Tg2576 APP-Tg mice

$\begin{array}{lccccc}\begin{array}{c}\text { No. of mice } \\ \text { per group }\end{array} & \begin{array}{c}\text { EAE } \\ \text { score }\end{array} & \begin{array}{c}\text { Anti-A } \beta \\ \text { antibody }^{A}\end{array} & \begin{array}{c}\text { Total brain } \\ \mathbf{A} \beta(\mathbf{n g} / \mathbf{g})\end{array} & \begin{array}{c}\% \text { Area of } \\ \text { thioflavin S-positive } \mathbf{A} \beta \\ \text { plaques (hippocampus) }\end{array} \\ \text { Control } & 5 & 0 & 0 & 1,682.8 \pm 334.1 & 2.67 \pm 0.4 \\ \text { PLP } & 5 & 1.7 \pm 0.7 & 0 & 672.1 \pm 53.6^{\mathrm{B}} & 0.68 \pm 0.2^{\mathrm{C}}\end{array}$

AThe results are presented as level of $\mathrm{OD}_{450}$ at a titer of 1:500 $\mathrm{lgG}$. Statistical analysis was performed using Student's $t$ test. ${ }^{B} P<0.02$ versus control (untreated mice). $\mathrm{C} P<0.002$ versus control.

question, we tested the effect of immunization of APP-Tg mice with GA, which is a random amino acid copolymer of alanine, lysine, glutamic acid, and tyrosine that is effective in suppression of EAE and is an approved and widely used treatment for relapsing forms of MS (23). There is some evidence that GA may have cross-reactivity with myelin basic protein (MBP) (26), although it has never been reported to induce EAE in animals, even when given with CFA. We thus investigated whether immunization of APP-Tg mice with GA in a fashion identical to that by which we induced EAE would reduce amyloid load in APP-Tg mice without inducing clinical disease. Mice were immunized with $100 \mu \mathrm{g} \mathrm{GA}$ in CFA, and immediately thereafter and at 48 hours, they received an i.p. injection of $150 \mathrm{ng}$ of PT. Fifty days after immunization, the brains were examined. We found that GA immunization led to a $92 \%$ reduction in thioflavin S staining for amyloid fibrils in the hippocampal region versus that in controls $(P<0.01)$ and a $70 \%$ reduction in total $\mathrm{A} \beta$ levels $(P<0.01$; Table 1 and Figure 1$)$. As expected, there was no clinical or neuropathological evidence of EAE in mice immunized with GA/CFA plus PT.

Clearance of $A \beta$ by nasal vaccination of GA plus a proteosome-based adjwvant. Our laboratory has been interested in vaccination strategies for noninfectious diseases using the mucosal immune system, an approach that is less invasive than parenteral administration and that is clinically applicable (27-29). We have previously demonstrated that nasal vaccination with $A \beta$ 1-40 peptide resulted in a $50-60 \%$ reduction in cerebral A $\beta$ burden in APP-Tg mice (5). To investigate the effect of nasal vaccination with GA in a mouse model of $\mathrm{AD}$, we treated animals with nasal GA alone or together with a mucosal adjuvant. For the latter, we used a proteosomebased mucosal adjuvant comprising purified outer membrane proteins of Neisseria meningitides and LPS (IVX-908; Protollin; ID Biomedical Corp.) that has been used safely in both humans (22) and mice $(30,31)$. APP-Tg mice received 4 nasal treatments the first week and then were boosted on a weekly basis for the next 5 weeks, after which neuropathological analysis was performed. As controls, APP-Tg mice were nasally treated with IVX-908 plus BSA, IVX-908 alone, or GA alone. We found that nasal administration of GA plus IVX908 (GA+IVX-908) resulted in an $84 \%$ reduction in thioflavin S-positive fibrillar amyloid in the hippocampus compared with control $(P<0.001)$ and a $70 \%$ reduction compared with treatment with IVX-908 alone $(P<0.01$; Table 3 and Figure 2). In terms of total brain $A \beta$

\section{Table 3}

levels, we observed a $73 \%$ reduction following nasal administration of GA+IVX-908 $(P<0.001)$ compared with control and a $45 \%$ reduction compared with treatment with IVX-908 alone $(P<0.002$; Table 3 and Figure 2). Nasal administration of GA alone did not affect $A \beta$ fibrils or total $A \beta$ levels in the brain (Table 3 and Figure 2). Nasal administration of BSA plus IVX908 or IVX-908 alone resulted in an approximately $50 \%$ reduction in total $\mathrm{A} \beta$ levels $(P<0.02$ vs. control), although there was no effect on fibrillar $A \beta$ staining. None of the animals developed clinical EAE.

Of note, there can be variability in the amount of amyloid deposition in the J20 strain depending on the age of the animal, especially in animals between the ages of 4 and 10 months (24). Nonetheless, we studied animals of the J20 strain that were older than 11 months of age and did not observe substantial increases in $A \beta$ deposition linked to age in the cohort we studied (A $\beta$ deposition values as determined both by ELISA and thioflavin $\mathrm{S}$ staining for individual mice in each treatment group and controls are presented in Supplemental Tables 1-3; supplemental material available online with this article; doi:10.1172/JCI23241DS1). Our experience is consistent with the reports of other investigators who did not find a large increase in $A \beta$ levels in animals between the ages of 12 and 15 months (32-34). Also, when we exactly age-matched our control group (13.3 months) with MOG-EAE animals and animals treated nasally with GA+IVX-908, we found a significant effect of treatment on $\mathrm{A} \beta$ levels measured by 2 methods $(P<0.001$; Supplemental Table 4). To definitively rule out an effect of age or sex and to test the effect of chronic administration of GA+IVX-908 given at an early stage of amyloid deposition, we tested age- and sex-matched littermates that received nasal treatment with GA+IVX-908 versus controls beginning at age 5 months. As shown in Figure 3, Table 4, and Supplemental Table 5, we found a highly significant reduction in the level of amyloid fibril ( $83 \%)$ in the brains of GA+IVX908-treated mice versus control animals $(P<0.0001)$. Thus, the marked decrease in total $A \beta$ load we observed was related to treatment, not to the age or sex of the animals, and also occurred when treatment was begun at an earlier stage of amyloid deposition.

Activated microglia colocalize with $A \beta$ fibrils and correlate with $A \beta$ clearance. To investigate the potential mechanisms by which $A \beta$ reduction occurred, we performed immunohistochemical analyses to assess microglial activation, $\mathrm{T}$ cell infiltration, and cytokine patterns in the brains of the immunized mice. We also investigated the types of cells in the hippocampus and their correlation with $A \beta$ fibrils.

Effect of nasal immunization on total and fibrillar A $\beta$ in the brains of J20 APP-Tg mice

$\begin{array}{lccccc} & \begin{array}{c}\text { No. of mice } \\ \text { per group }\end{array} & \begin{array}{c}\text { EAE } \\ \text { score }\end{array} & \begin{array}{c}\text { Anti-A } \beta \\ \text { antibody }\end{array} & \begin{array}{c}\text { Total brain } \% \\ \mathbf{A} \beta(\mathbf{n g} / \mathbf{g})\end{array} & \begin{array}{c}\text { Area of thioflavin } \\ \text { S-positive } \mathbf{A} \beta \\ \text { plaques (hippocampus) }\end{array} \\ \text { ControlA } & 7 & 0 & 0 & 1,409.4 \pm 152.7 & 2.9 \pm 0.4 \\ \text { GA } & 4 & 0 & 0 & 1,016.6 \pm 81.0 & 2.06 \pm 0.8 \\ \text { IVX-908 } & 7 & 0 & 0 & 648.1 \pm 84.1^{B} & 1.5 \pm 0.2 \\ \text { GA+IVX-908 } & 8 & 0 & 0 & 402.7 \pm 70.5^{C} & 0.48 \pm 0.09 \mathrm{D}\end{array}$

AResults are presented as level of $\mathrm{OD}_{450}$ at titer of 1:500 lgG. Statistical analysis was performed using 1-way ANOVA with Bonferroni correction. ${ }^{\mathrm{B} P}<0.02$ versus control. ${ }^{\mathrm{C} P}<0.001$ versus control. ${ }^{D} P<0.001$ versus control; $P<0.05$ versus $\mathrm{GA}$. 


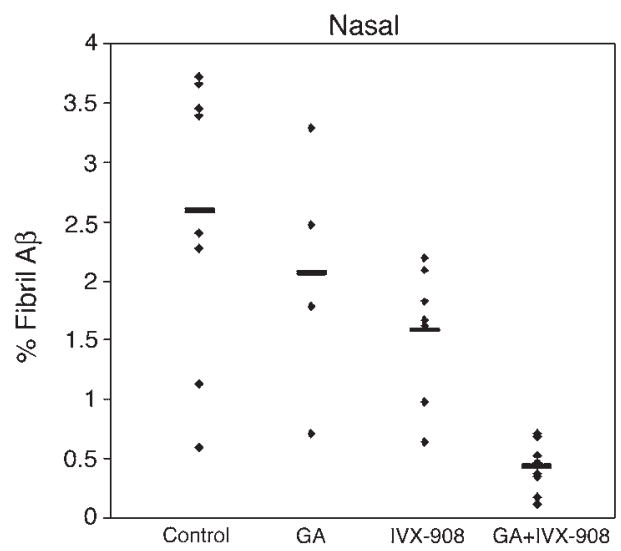

\section{Figure 2}

Effect of nasal immunization on fibril $A \beta$ levels in the brain. To measure $A \beta$ fibrils, the left hemisphere of each mouse was cut into $14-\mu \mathrm{m}$ longitudinal sections and stained with thioflavin S. Multiple sections from the identical regions were examined for each treatment group. The quantification was performed in a blinded fashion using Imaging Research software from the NIH. $P<0.001, \mathrm{GA}+\mathrm{IVX}-908$ versus control; $P<0.001$ versus GA.

Previous studies have suggested that activated microglia may play an important role in clearing $A \beta$ in vivo $(9,20,35)$. To investigate the potential role of microglial activation in the $\mathrm{A} \beta$ clearance we observed after subcutaneous or nasal immunization of APP-Tg mice, we stained the brains of mice with CD11b, a marker of activated microglia. As shown in Figures 4 and 5 and Table 5, immunostaining of the hippocampus revealed increased numbers of activated microglia following MOG immunization in APP-Tg mice compared with control mice $(P<0.02)$. The activated microglia we observed tended to colocalize with $A \beta$ plaques. Furthermore, increased levels of microglia activation were also observed in B cell-deficient mice $(P<0.001)$ (Table 5$)$. In addition, we found activated microglia surrounding the amyloid plaques following GA immunization (Figure 4).

We then investigated whether the microglial activation we observed in immunized APP-Tg mice was also observed in wildtype (non-Tg) mice immunized with GA or IVX-908. We found no microglial activation in non-Tg littermates in any of the immunization protocols: parenterally with CFA/PT plus GA, nasally with GA+IVX-908 (see Figure 4B), or nasally with IVX-908 alone. These results suggest that the activation of microglia by GA or IVX-908 immunization was dependent on the presence of amyloid deposition, which primed endogenous microglia for further activation.

Although there is no known cross-reactivity between GA and A $\beta$ and we did not observe anti-A $\beta$ antibodies in either GA-treated or EAE animals, it is possible that immunization with GA+ IVX-908 could have resulted in priming of $A \beta$-reactive $T$ cells. We measured $\mathrm{T}$ cell proliferative responses and production of cytokines (IL-2, IFN- $\gamma$, IL-6) after 6 weeks of weekly treatment with GA+IVX-908 (at which time the experiment was terminated) by stimulating splenic $T$ cells with $A \beta 1-40$. We found no priming of $A \beta$ reactive $T$ cells as measured by proliferation: counts per minute in response to $\mathrm{A} \beta$ for untreated, 3,315 $\pm 1,682$; for GA+IVX-908, 4,566 $\pm 1,412$ (background counts were 100-300 cpm). The stimulation index (GA+IVX-908-treated/untreated) was 1.37; a minimal stimulation index of greater than 2.5 is considered positive. Furthermore, we did not find secretion of IL-2, IFN- $\gamma$, or IL- 6 above background in these cultures. This lack of $\mathrm{T}$ cell response to $\mathrm{A} \beta$ is consistent with the fact that we did not detect anti-A $\beta$ antibodies, as T cell help is required for production of antibodies. Similarly, we did not find priming in response to $A \beta$ in EAE animals. We also examined the immune response to GA in the spleen 10 days after nasal GA+IVX908 treatment and found proliferative responses to GA (stimulation index, $6.4 ; 11,440 \pm 1,171 \mathrm{cpm})$ plus secretion of IFN- $\gamma(4,990$ $\mathrm{pg} / \mathrm{ml}), \mathrm{IL}-10(156 \mathrm{pg} / \mathrm{ml})$, and IL-2 $(966 \mathrm{pg} / \mathrm{ml})$.

To examine the effect of GA+IVX-908 treatment on other brain sites besides the hippocampus, we investigated the olfactory bulb and the cerebellum. We stained the olfactory bulb for A $\beta, C D 11 b$, and fibrinogen and obtained results similar to those observed in the hippocampus (Figure 6). Following nasal administration of GA+IVX-908, we found an increased number of activated microglia compared with control. The activation also occurred in animals with EAE, but was associated with leakage in the blood-brain barrier (BBB), as measured by staining for fibrinogen (Figure 7).

When we examined the cerebellum, we did not find increased activation of microglial staining in GA+IVX-908-treated animals, which suggests that the increased activation is restricted to areas with $A \beta$ deposition. Furthermore, no activation of microglia was observed anywhere in the brains of non-Tg littermates following GA+IVX-908 treatment, which further demonstrates that the increased activation is restricted to areas with $A \beta$ deposition (see Figure 4B).

To better understand the mechanism of the clearance we observed, we stained for CD68, which is highly expressed on activated macrophages from the periphery as opposed to brain microglia. As shown in Figure 8, we obtained higher staining for CD68 in animals with EAE compared with those treated with GA+IVX-908. This pattern of staining shows the migration of macrophages from the choroid plexus to the surrounding brain parenchyma including the cerebel-
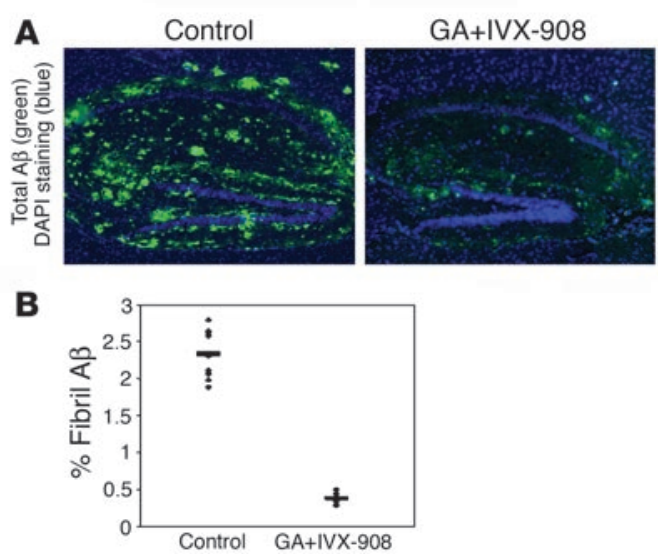

\section{Figure 3}

Nasal administration of GA+IVX-908 reduces amyloid levels in the brains of age- and sex-matched littermates treated for 8 months. Ageand sex-matched littermates from J20 APP-Tg mice were treated weekly beginning at 5 months of age with GA+IVX-908 or PBS and were sacrificed at age 14 months. (A) Staining for total $A \beta$ with anti$A \beta$ antibody in typical hippocampal sections from treated and control (PBS-treated) animals (magnification, $\times 10$ ). (B) Reduction in the levels of amyloid fibril in the hippocampal region of GA+IVX-908-treated mice versus controls $(P<0.0001)$. Fibrillar $\mathrm{A} \beta$ levels in sections of the hippocampal region from individual mice following nasal treatment measured by staining with thioflavin S. 


\section{Table 4}

Reduction in the levels of amyloid fibril in the hippocampal region of GA+IVX-908-treated mice versus age- and sex-matched controls treated for 8 months

$\begin{array}{lccc} & \begin{array}{c}\text { No. of mice } \\ \text { per group }\end{array} & \text { Sex } & \begin{array}{c}\% \text { Area of thioflavin S-positive } \\ \text { A } \beta \text { plaques (hippocampus) }\end{array} \\ \text { Control } & 9 & & 2.3 \pm 0.11 \\ & 5 & \text { M } & 2.2 \pm 0.14 \\ \text { GA+IVX-908 } & 4 & \text { F } & 2.5 \pm 0.16 \\ & 8 & & 0.4 \pm 0.03 \\ & 5 & \text { M } & 0.4 \pm 0.02 \\ & 3 & \text { F } & 0.4 \pm 0.06\end{array}$

To measure $A \beta$ fibrils, the left hemisphere of each mouse was cut to 14-um longitudinal sections and stained with thioflavin S. Multiple sections from the identical regions were examined for each treatment group. Quantification was performed in a blinded fashion using Imaging Research software from the NIH. $P<0.001, \mathrm{GA}+\mathrm{IVX}-908$ versus control (Student's $t$ test).

lum and cortex. With GA+IVX-908 treatment, there was increased expression of CD68, primarily in the choroid plexus space. This suggests that the $C D 11 b^{+}$cells responsible for clearance of $A \beta$ in animals with EAE migrate to the CNS from the periphery and are associated with neuronal toxicity, whereas the CD11 ${ }^{+}$cells in GA+IVX-908-treated animals are primarily endogenous microglial cells and are associated with clearance of $A \beta$ without evidence of direct toxicity. As further support for this interpretation, we found that there was increased expression of $\mathrm{CD} 68^{+}$cells in the cerebellum of animals with EAE but not GA+IVX-908-treated or untreated animals (data not shown). Moreover, activated CD11 $\mathrm{b}^{+}$cells following GA+IVX-908 treatment were only found in regions where there was accumulation of amyloid.

As shown in Table 5 and Figure 5, the reduction of $A \beta$ fibrils in the hippocampus was strongly correlated with increased numbers of both activated microglial cells, as shown by CD11b staining $(r=-0.7$, CD11b vs. A $\beta$ fibrils), and IFN- $\gamma$-secreting cells $(r=-0.8$, IFN- $\gamma$ vs. A $\beta$ fibrils $)$. There was a strong correlation between $\mathrm{CD} 11 \mathrm{~b}$ cells and IFN- $\gamma$-secreting cells $(r=0.9)$. In addition, as with CD11b and IFN- $\gamma$ cells, we observed increased numbers of microglia immunoreactive for M-CSF receptor (M-CSFR) in treated animals compared with controls $(P<0.02$; Table 5$)$. We observed a reduction in TGF- $\beta$ expression in MOG- $(P<0.02)$ and GA+IVX-908-treated mice $(P<0.001)$ compared with controls (Table 5). Furthermore, there was a strong correlation between reduction in TGF- $\beta$ expression and the percentage of $A \beta$ fibril in the hippocampus region $(r=0.91)$. No significant changes were observed in levels of IL-10-immunoreactive cells between control and GA+IVX-908-treated animals, although animals with EAE had lower levels of IL-10 than controls.

Reduction in astrocytosis and neurotoxicity following nasal vaccination with GA+IVX-908. In order to investigate toxicity and potential negative effects of therapy after 6 weeks of treatment, we examined the following: (a) glial fibrillary acidic protein (GFAP), a marker
A

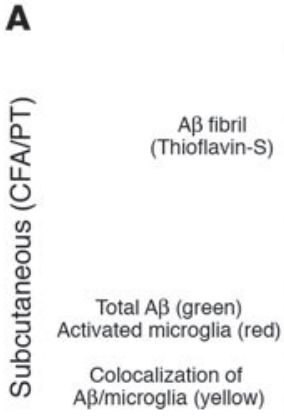

B
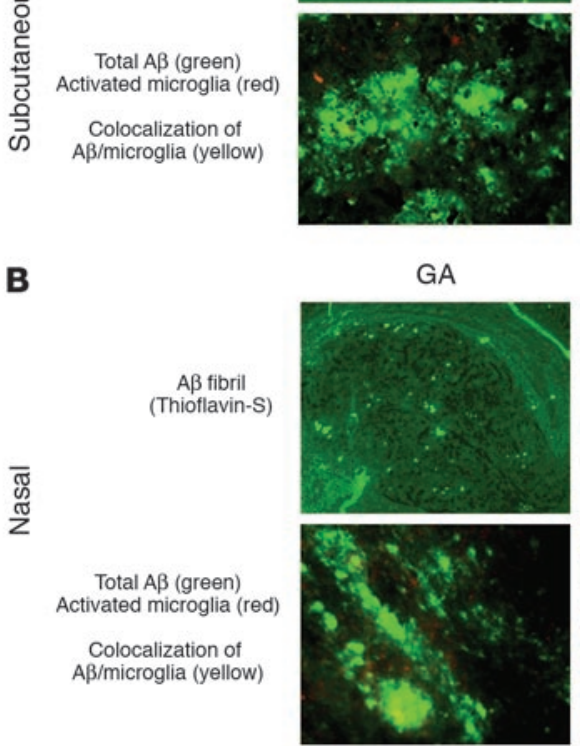

GA

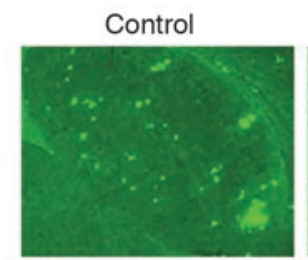

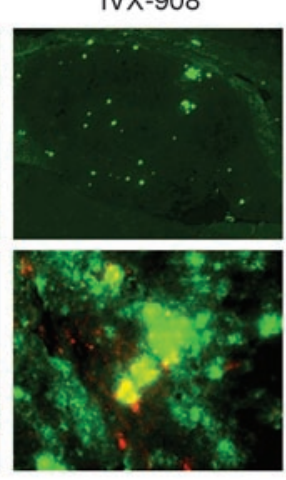

$A \beta 1-40$
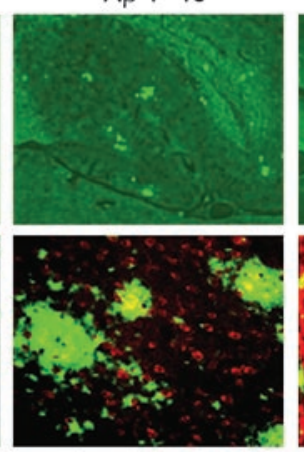

IVX-908

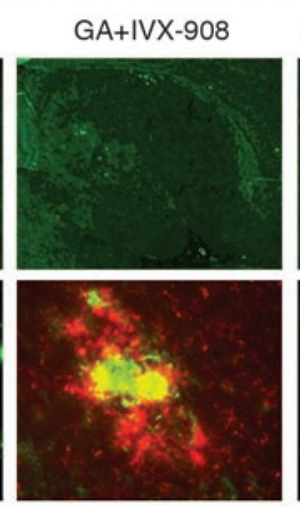

MOG
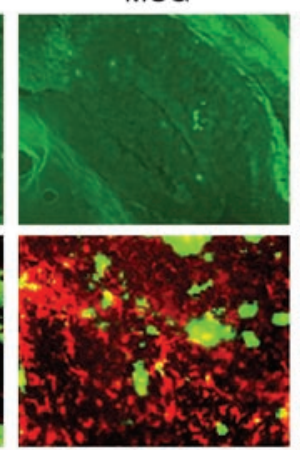

GA+IVX-908 non-Tg

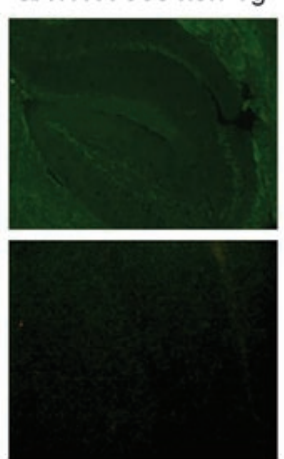

Figure 4

Activation of $C D 11 b^{+}$cells leads to clearance of $A \beta$ fibril in parenterally and nasally treated mice. (A) Staining of $A \beta$ fibril in hippocampal region with thioflavin $S$ (magnification, $\times 10$ ) or costaining for total $A \beta$ with anti-A $\beta$ antibody (R1288) and anti-CD11b (microglia/macrophage) (magnification, $\times 40$ ) following subcutaneous immunization compared with control (see Table 1). (B) Costaining of anti-A $\beta$ antibody (R1288) and anti-CD11b (microglia/macrophage) in hippocampal region (magnification, $\times 40$ ) following nasal immunization. 

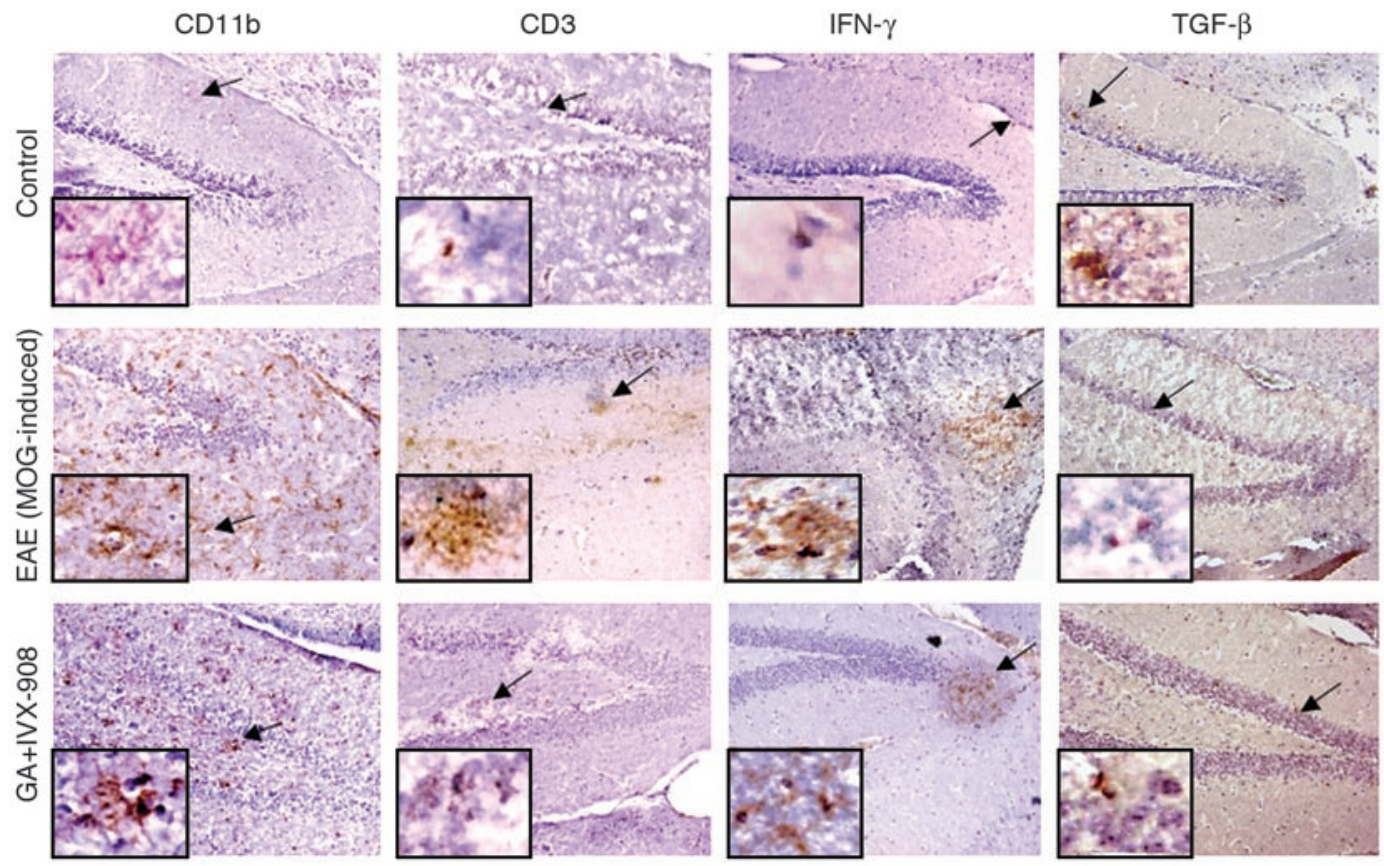

\section{Figure 5}

Immunohistology of brain sections following subcutaneous MOG immunization and nasal vaccination with GA+IVX-908. Serial sections of the hippocampus region from untreated or immunized mice 50 days after immunization were labeled using anti CD11b, CD3, IFN- $\gamma$, and TGF- $\beta$ antibodies (magnification $\times 20$; insets, $\times 60$ ).

of astrocytosis that occurs in response to neuronal damage; (b) SMI32, a marker for phosphorylation of neurofilaments, which increases with neuronal damage; (c) TUNEL, a marker of the apoptotic death cascade; (d) iNOS, an enzyme that is upregulated when there is stress to neuronal cells.

Astrocytosis (determined as the area of activated astrocytes as indicated by the presence of $\mathrm{GFAP}^{+}$cells) occurred in untreated control animals (Figure 9). Astrocytosis was reduced when GA+IVX-908 was given nasally $(3.1 \% ; P=0.039$ vs. control). It was not reduced in EAE animals (even though there was clearance of $A \beta$ in EAE animals). Thus, clearance of $A \beta$ by $\mathrm{GA}+\mathrm{IVX}-908$ is associated with reduced astrocytosis.

SMI32-positive cells associated with neuritic plaques that have an abnormal ovoid morphology were observed in control animals (Figure 10). In EAE mice, although there were no neuritic plaques, there was increased SMI32 cells with abnormal ovoid morphology throughout the brain in association with inflammation. In GA+IVX-908-treated animals, there was a reduction in SMI32-positive cells with abnormal ovoid morphology in neuritic plaques. Thus, GA+IVX 908 treatment is not associated with toxicity as measured by SMI32.
Table 5

Immunohistochemistry of hippocampus in immunized animals

We found no TUNEL staining in control animals and increased TUNEL staining in the cortex of EAE animals (Figure 10). No TUNEL staining was observed in GA+IVX-908-treated animals. A staining pattern similar to that of TUNEL was observed with iNOS, viz, upregulation in EAE mice and no upregulation in GA+IVX908-treated animals. Furthermore, we examined BBB integrity by staining for the serum protein fibrinogen (36). We found no

\begin{tabular}{|c|c|c|c|c|c|c|}
\hline & \multicolumn{6}{|c|}{ No. of cells per mm² hippocampal region ${ }^{A}$} \\
\hline & CD11bB $^{B}$ & $\mathrm{CD}^{\mathrm{C}}$ & M-CSFRD & $\mathrm{IFN}-\gamma^{\mathrm{E}}$ & TGF- $\beta$ F & IL-10G \\
\hline $\begin{array}{l}\text { Control } \\
\text { Subcutaneous (CFA/PT) }\end{array}$ & $76 \pm 17$ & $5 \pm 3$ & $11 \pm 4$ & $7 \pm 3$ & $73 \pm 12$ & $64 \pm 6$ \\
\hline$A \beta$ & $106 \pm 27$ & $10 \pm 2$ & $34 \pm 11$ & $9 \pm 2$ & $41 \pm 5$ & $44 \pm 5$ \\
\hline MOG & $349 \pm 34.3^{H}$ & $142 \pm 19^{H}$ & $79 \pm 51$ & $109 \pm 7^{H}$ & $20 \pm 5^{\jmath}$ & $21 \pm 9^{k}$ \\
\hline MOG B cell-deficient & $462 \pm 23^{H}$ & $195 \pm 12^{\mathrm{H}}$ & $77 \pm 6$ & $119 \pm 18^{H}$ & $22 \pm 8^{K}$ & $25 \pm 51$ \\
\hline $\begin{array}{l}\text { GA } \\
\text { Nasal }\end{array}$ & $227 \pm 61^{1}$ & $61 \pm 12^{\prime}$ & $57 \pm 8$ & $85 \pm 11^{H}$ & $31 \pm 7$ & $59 \pm 7$ \\
\hline GA & $136 \pm 12$ & $35 \pm 19$ & $30 \pm 9$ & $53 \pm 31$ & $77 \pm 10$ & $75 \pm 7$ \\
\hline IVX-908 & $406 \pm 16^{\mathrm{H}}$ & $55 \pm 91$ & $81 \pm 16$ & $92 \pm 4^{H}$ & $40 \pm 11$ & $62 \pm 11$ \\
\hline GA+IVX-908L & $451 \pm 48^{\mathrm{H}}$ & $67 \pm 9^{k}$ & $119 \pm 30^{\mathrm{H}}$ & $81 \pm 10^{\mathrm{J}}$ & $14 \pm 2^{\mathrm{H}}$ & $58 \pm 8$ \\
\hline
\end{tabular}

AData represent quantification of 3 sections for each treatment and 6 sections for the control ( 3 untreated plus 3 BSA/CFA-treated as described in Table 1). Statistical analysis was performed using the 1-way ANOVA, Bonferroni test. ${ }^{B} r=-0.7, C D 11 b$ versus percent area of $A \beta$ fibril. ${ }^{C} r=-0.65, C D 3$ versus percent area of $\mathrm{A} \beta$ fibril; $r=0.74$, CD3 versus $\mathrm{CD} 11 \mathrm{~b}$. $\mathrm{D} r=-0.7, \mathrm{M}-\mathrm{CSFR}$ versus percent area of $\mathrm{A} \beta$ fibril; $r=0.92$, M-CSFR versus CD11b. $\mathrm{E} r=-0.8$, IFN- $\gamma$ versus percent area of $\mathrm{A} \beta$ fibril; $r=0.9$, IFN- $\gamma$ versus CD11b; $r=0.85, \mathrm{IFN}-\gamma$ versus CD3. $\mathrm{F} r=0.91$, TGF- $\beta$ versus percent area of $\mathrm{A} \beta$ fibril; $r=-0.77$, TGF- $\beta$ versus CD11b; $r=-0.6$, TGF- $\beta$ versus CD3. ${ } r=0.67$, IL-10 versus percent area of A $\beta$ fibril; $r=-0.4$, IL-10 versus CD11b. ${ }^{H} P<0.001$ versus control. ${ }^{I} P<0.05$ versus control. $J P<0.01$ versus control. $\mathrm{K} P<0.02$ versus control. $\stackrel{\mathrm{L} P}{ } P=0.0007, \mathrm{CD} 11 \mathrm{~b}$ versus $\mathrm{GA} ; P<0.05$, IFN- $\gamma$ versus $\mathrm{GA} ; P=0.0011$, TGF- $\beta$ versus $\mathrm{GA}$. 

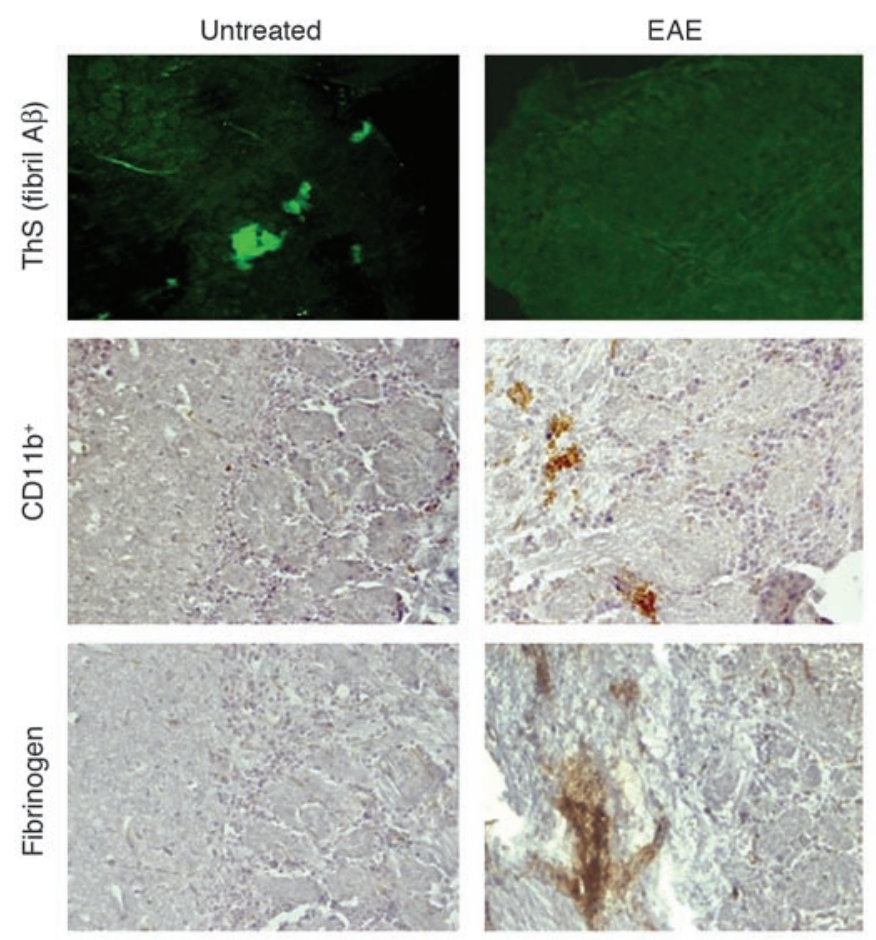

damage to the integrity of the BBB in GA+IVX-908-treated mice in either the hippocampus or the olfactory bulb (Figures 6 and 7). As would be expected, BBB breakdown was observed in EAE mice. The GA+IVX-908-treated animals exhibited no changes in the behavior, as measured by body weight, eating habits, tail tone, or mobility, that indicated toxicity. Such changes were, however, observed in EAE animals. GA+IVX-980 treatment did not lead to mortality in any of the animals studied. Of note, in an ongoing, long-term experiment, we have observed no behavioral changes in animals that have been treated weekly with GA+IVX-908 for 8 months as described in Figure 3.

\section{Discussion}

In the present study, we investigated a novel immunotherapeutic approach for the reduction of $A \beta$ in a mouse model of $A D$. We found that induction of EAE in APP-Tg mice reduces amyloid load in the brain in an antibody-independent fashion. This effect could be reproduced without induction of EAE using GA given parenterally or nasally with an adjuvant. GA is an FDA-approved drug used
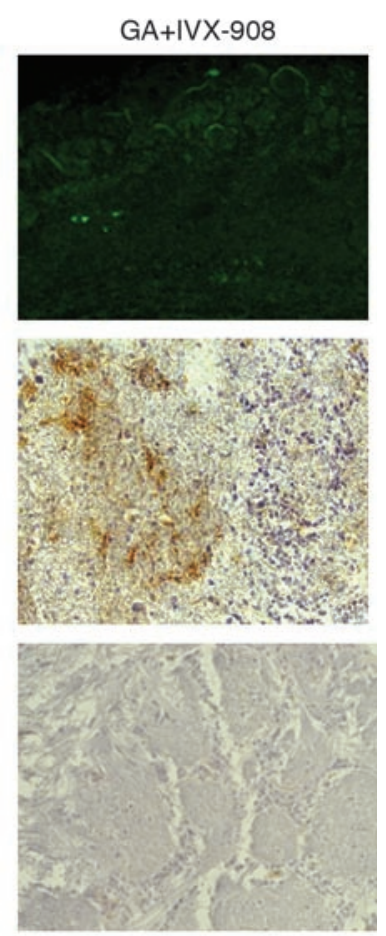

\section{Figure 6}

Neuropathology in olfactory sections following subcutaneous immunization with MOG and nasal vaccination with GA. Serial sections of the cortex from untreated or treated mice 50 days after immunization were stained for fibril amyloid using thioflavin S (ThS), for microglia activation using antiCD11b antibodies, and for BBB integrity using anti-fibrinogen antibodies. Magnification $\times 20$.

for the treatment of relapsing-remitting MS. The mechanism of action of GA in MS appears to be related to its induction of $\mathrm{T}$ cells that secrete antiinflammatory cytokines that mediate bystander suppression in the CNS (26). Furthermore, GA has been shown to be of benefit in experimental models of CNS trauma (37), optic nerve injury (38), amyotrophic lateral sclerosis (39), and Parkinson disease (40). The mechanism of action in these models is not known, although it may relate to the induction of T cells that release growth factors and/or IFN- $\gamma$ (38).

In previous studies involving mouse models of $\mathrm{AD}$ in which animals were immunized with $\mathrm{A} \beta$ in CFA, anti-amyloid antibodies were shown to have a key role both in vitro $(11,12,17)$ and in vivo (4-9) in reducing amyloid load. The presence of anti-A $\beta$ antibodies and microglia-like cells that were immunopositive for amyloid has led to the speculation that clearance of $A \beta$ is the result of FcR-mediated phagocytosis by microglia of anti-A $\beta$ and $A \beta$ immune complexes. Since microglia are phagocytic cells, it has been suggested that microglia may function as plaque-attacking scavenger cells (41).

We believe that activation of microglia is the final common pathway for $A \beta$ clearance in our immunization experiments. It has been reported that increased expression of M-CSFR in mouse and human microglia accelerates phagocytosis of aggregated $\mathrm{A} \beta$, through increasing both expression of macrophage scavenger receptors and/or microglial expression of $\mathrm{FcR} \gamma$ (42). As we observed robust clearance of $A \beta$ in $B$ cell-deficient mice that also had increased staining for M-CSFR, the effects we observed are

\section{Figure 7}

BBB integrity in hippocampus section following subcutaneous immunization with MOG and nasal vaccination with GA. Serial sections of the cortex from untreated or treated mice 50 days after immunization were labeled using fibrinogen, a marker of plasma staining. Labeling for markers of fibrinogen was observed in EAE animals but not in GA+IVX-908-treated animals. Magnification, $\times 10$ (upper panels) and $\times 20$ (lower panels).
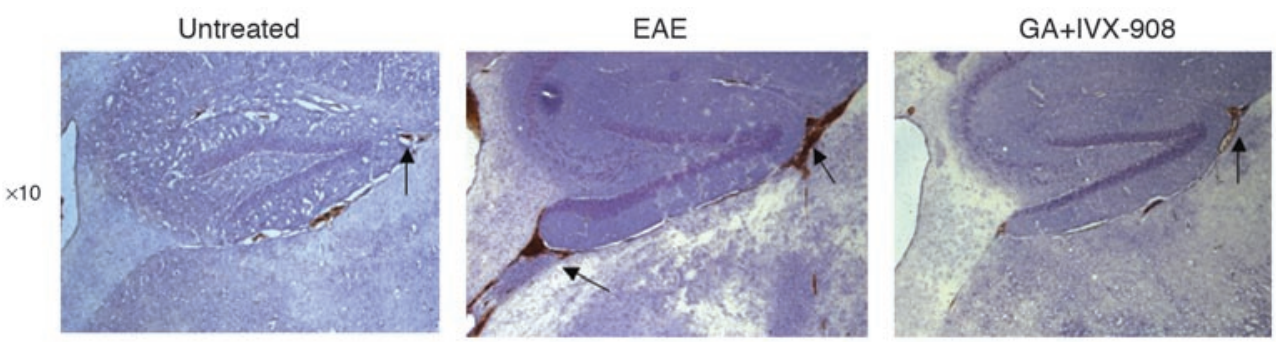

$\times 20$

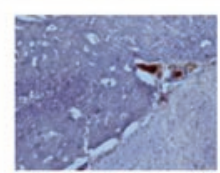

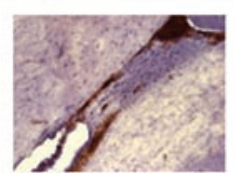

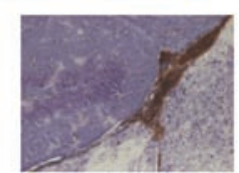



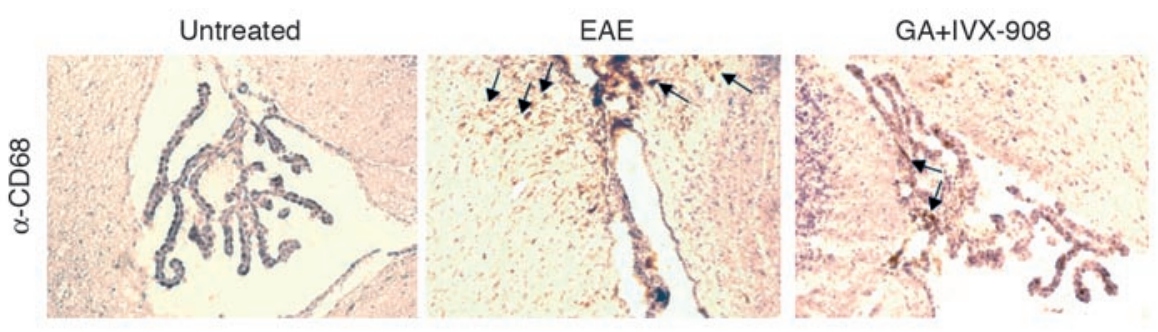

\section{Figure 8}

Staining for $\mathrm{CD}^{+} 8^{+}$cells in the CNS in untreated, MOG-immunized, and GA+IVX-908-treated mice. Arrows indicate $\mathrm{CD} 68^{+}$cells, which infiltrated the CNS in EAE but remained localized to choroid plexus in GA+IVX-908-treated mice. No staining was observed in untreated mice. Sections were taken from the cerebellum. Magnification, $\times 20$. occurring via a non-Fc-mediated mechanism $(43,44)$. Microglial activation by subcutaneous or nasal vaccination was correlated with increased numbers of $\mathrm{T}$ cells, which may play a role in promoting microglial activation, as there was a correlation between numbers of T cells and numbers of IFN- $\gamma$-secreting cells. Previous studies have reported that TGF- $\beta$ may either increase or reduce A $\beta$ fibril formation in the APP-Tg mouse $(45,46)$. We observed a reduction in TGF- $\beta$ expression in MOG- and GA+IVX-908-treated mice compared with controls. Furthermore, there was a strong correlation between a reduction in TGF- $\beta$ expression and the percentage of $A \beta$ fibril in the hippocampus region.

In the case of EAE, we postulate that Th1-type myelin-reactive $T$ cells are activated in the periphery by immunization with MOG or PLP plus CFA, and these T cells migrate to the brain, where they release IFN- $\gamma$ and activate microglia. Encephalomyelitis and paralysis of animals results from damage to myelin and underlying axons. Immunization with BSA/CFA in the periphery did not lead to A $\beta$ clearance because BSA-specific Th1-type cells do not accumulate in the brain. Peripheral immunization with GA in CFA induces GA-specific T cells that have been shown in the EAE model to accumulate in the brain due to cross-reactivity with MBP (26) and that, we hypothesize, accumulate in the brains of immunized APP-Tg animals. These T cells are then able to secrete IFN- $\gamma$ and activate microglia but are unable to cause EAE because of altered affinity for MBP and the concomitant secretion of antiinflammatory cytokines (26). Nasal administration of IVX908 alone leads to some clearance of $\mathrm{A} \beta$, as it is able to activate microglia through its LPS effects. It was reported that injection of LPS into the hippocampus can cause clearance of $A \beta$ (47). Nevertheless, IVX-908 alone did not clear A $\beta$ as efficiently as the combination of IVX-908 plus GA, which may be a stronger activator of $\mathrm{T}$ cells than LPS. Importantly, in non-Tg mice, no microglia activation was observed when GA was given parenterally with CFA or intranasally with IVX-908. A $\beta$ deposition leads to partial activation of microglia surrounding the plaque, and it appears that this activation is a prerequisite for microglia to be further activated by GA+IVX-908. It is possible that partial activation of microglia is associated with the expression of IFN- $\gamma$ or Toll-like receptors that prime microglia for further activation by IVX-908 (35). It was reported (48) that Protollin could be stimulating the microglial cells both through LPS via TLR-4 and through Por B, which makes up $70 \%$ of the proteosome protein and is known to activate APCs via TLR-2.

In previous studies (5) in which we nasally administrated $A \beta$ peptide without an adjuvant, the mechanism of $A \beta$ clearance was postulated to be the induction of anti-A $\beta$ antibodies, as there was a correlation between antibody levels and $A \beta$ clearance. We also found a small number of cells that secreted IL-10 and TGF- $\beta$ in the brain. These types of cells are preferably induced following mucosal administration of antigen. In the present work, we immunized nasally using GA or parenterally using myelin antigens or GA in Th1-type adjuvants. The reduction in $A \beta$ levels in the present study was related to cellular mechanisms associated with IFN- $\gamma$ in the brain and a reduction in the expression of the antiinflammatory cytokine TGF- $\beta$ (no changes were observed for IL-10). Thus, the mechanism of action leading to $A \beta$ clearance and the antigens used for nasal or parenteral immunization in the present study are quite distinct from those in our prior work.

Moreover, even though there was clearance of $\mathrm{A} \beta$ both in EAE and with GA+IVX-908 treatment, GA+IVX-908 treatment was not associated with the neuronal toxicity that was observed in EAE. Furthermore, there was an actual reduction in astrocytosis in the GA+IVX-908 treated animals compared with untreated control animals. In our studies, we did not measure cognitive function, though others have shown improvement in cognitive tasks in animals that have had a lowering of $A \beta$ levels $(6,7,49)$.

When considering immune-based therapy for the treatment of $\mathrm{AD}$, one must carefully consider the pros and cons of any such therapy, given the untoward side effects that occurred following immunization with $A \beta$, a therapy designed to induce anti-A $\beta$ antibodies. A major question that arises regarding the antibodyindependent strategy we have described is whether the induction of an inflammatory response in the brains of humans that includes a Th1 component will have untoward side effects (50-52). It is postulated that the meningoencephalitis observed following $\mathrm{A} \beta$ immunization was related to the induction of $A \beta$-reactive $T$ cells, and we have shown that there is increased $\mathrm{T}$ cell reactivity to $A \beta$ in elderly individuals (53). In our animal studies, in which we induced EAE or nasally administered GA+IVX-908, we did not observe induction of anti-A $\beta$ antibodies or priming of anti-A $\beta \mathrm{T}$ cells, though the latter remains a possibility.

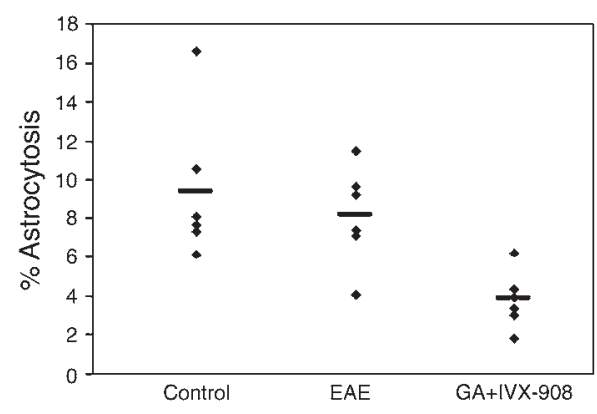

\section{Figure 9}

Reduction in astrocytosis following nasal administration of GA+IVX908. Well-defined hippocampal regions (bregma $-1.44 \mathrm{~mm}$ ) were selected for quantification of activated astrocytes using anti-GFAP staining. The level of astrocyte activation was expressed as a percent per $\mathrm{mm}^{2}$ hippocampal region. $P=0.039, \mathrm{GA}+\mathrm{IVX}-908$ versus control; $P=0.02, \mathrm{GA}+\mathrm{IVX}-908$ versus EAE (MOG-induced). 


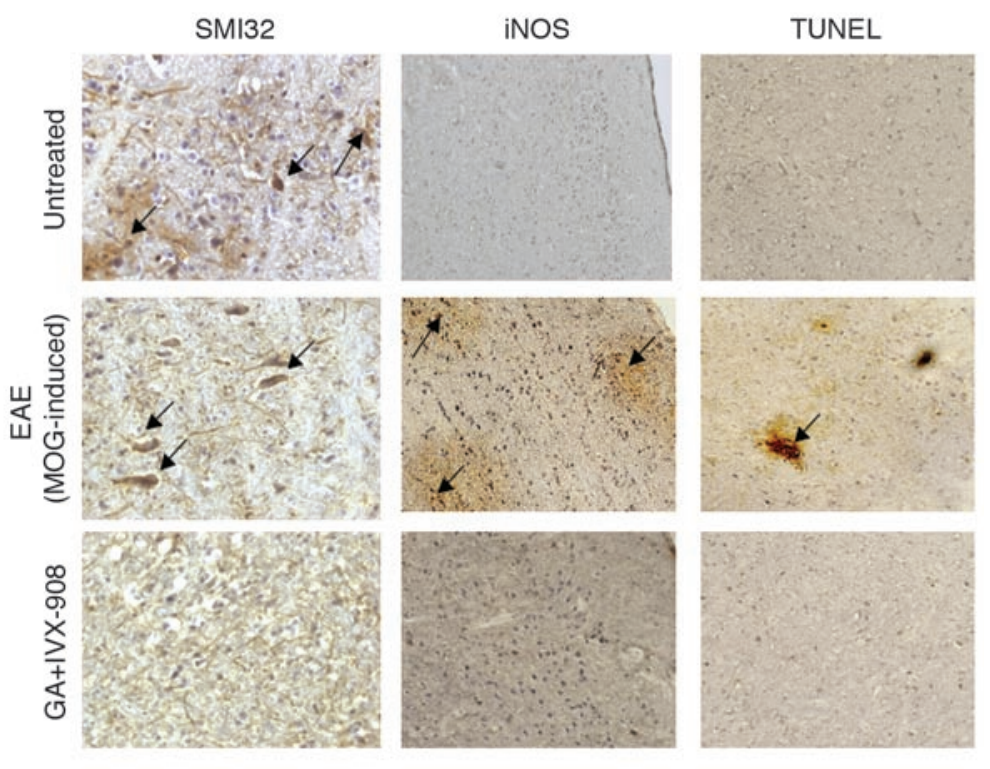

\section{Figure 10}

Neuropathology in brain sections following subcutaneous immunization with MOG and nasal vaccination with GA. Serial sections of the cortex from untreated or treated mice 50 days after immunization were labeled using markers of neurotoxicity: SMI32, iNOS, and TUNEL (original magnification, $\times 20$ ). Arrows identify labeling for markers studied. Labeling for markers of neurotoxicity was observed in EAE animals but not in GA+IVX-908-treated animals.

example cited above, in humans there are instances of microglial reaction to amyloid, yet no apparent clearance as has been observed with AD patients that have had multiple bouts of inflammatory disease before they die. Thus, the controlled inflammatory stimuli we have produced in our mouse studies may not lead to significant clearance of amyloid in humans.

Despite the fact that we did not observe toxicity in animals given GA+IVX-908, it must be pointed out that $\mathrm{AD}$ is a chronic disease, and chronic administration of GA+IVX-908 might cause side effects that we did

Inflammation, in itself, is not a specific hallmark of disease, and as a host defense mechanism, it may have beneficial effects, as we have demonstrated in our studies. Furthermore, inflammatory processes may differ. We observed a clear difference in the type of inflammation in EAE animals and those treated nasally with GA+IVX-908, even though both led to clearance of $A \beta$. In EAE, there was breakdown of the $\mathrm{BBB}$, no reduction in astrocytosis, evidence of neuronal death, and nitric oxide oxidative stress. None of these effects of inflammation was observed with nasal GA+IVX-908 treatment.

We have demonstrated clearance of $A \beta$ in association with microglia activation. It should be pointed out that microglial activation can have both positive and negative effects (54). Microglia represent a natural mechanism by which protein aggregates and debris can be removed from the brain, and there are reports that microglial activation following $A \beta$ immunization or stroke may lead to $A \beta$ clearance $(20,55)$. In animal studies, Wyss-Coray and colleagues (32) demonstrated that there is prominent neurodegeneration and increased plaque formation in the complementinhibited AD mouse model, in which microglia were significantly less activated than in wild-type $\mathrm{AD}$ mice at the same age. This supports the concept that activated microglia have a beneficial role in decreasing amyloid load without causing major neurotoxicity in the AD mouse model.

In an $\mathrm{AD}$ patient with stroke, Akiyama and McGeer (55) reported a local reduction in senile plaques in a neocortical region affected by incomplete ischemia and suggested that their findings and those reported by Nicoll et al. (20) could be related to phagocytosis of amyloid by highly reactive microglia. We have reported elevation of reactive microglia (CD11 $\mathrm{b}^{+}$cells) in ischemic area following stroke model in mouse (29). Nonetheless, there could be dysfunction of microglia in $\mathrm{AD}(56)$, and activation of microglia could lead to further damage.

Although we observed clearance of amyloid fibrils in association with microglial activation, it should be kept in mind that there are differences in the biochemical and solubility characteristics between amyloid deposits in mice and humans (57). Due to posttranslational processes, amyloid peptides in humans are considerably more derivative and thus more insoluble. Despite the stroke not observe in our animal studies. Nonetheless, the fact that we observed a decrease in $A \beta$ load even after treatment for 6 weeks raises the possibility that clinical effects may be observed after a short period of therapy in humans. Furthermore, since we also found reduction of $A \beta$ without behavior changes in animals given GA+IVX-908 for 8 months, it is possible that chronic human therapy may be well tolerated.

In summary, our results define a novel immune therapeutic approach for the treatment of $\mathrm{AD}$ that is antibody independent and is mediated by activated microglia. By combining an approved immunomodulatory drug used to treat MS with a nasal adjuvant, we were able to activate microglia and clear $\mathrm{A} \beta$ with 2 compounds that have been used in humans with no toxicity; however, it should also be pointed out that although IVX-908 and GA have been given to humans without toxicity, they have not been tested given together. Given the potential side effects described above, they should be cautiously applied in human studies. Nonetheless, in view of studies showing that immune-mediated reduction of cerebral A $\beta$ leads to cognitive improvement in APP-Tg mice, our finding that a novel vaccination approach clears $A \beta$ in older Tg mice with no apparent toxicity in animals, provides a new avenue for immune therapy that might prove efficacious in the treatment of $\mathrm{AD}$.

\section{Methods}

Mice. (B6XD2) $\mathrm{F}_{1}$ (average age 14 months) or (B6XSJL) $\mathrm{F}_{1}$ APP-Tg (WT) (average age 16 months) APP-Tg mice were housed and used in a pathogenfree facility at the Brigham and Women's Hospital (see supplemental tables for ages of individual mice for each group). All animal experiments were approved by the Harvard Medical Area Standing Committee on Animals.

Materials. IVX-908 (Protollin) is a non-covalent formulation of outer membrane proteins (proteosomes) of Neisseria meningitides and LPS from Shigella flexneri that has been safely tested in humans (22) and was obtained from ID Biomedical Corp. GA (Copaxone, TEVA Neuroscience Inc.) is a random amino acid copolymer of alanine, lysine, glutamic acid, and tyrosine that is an approved and widely used treatment for relapsing forms of MS (23) and was obtained from the Brigham and Women's Hospital pharmacy. MOG 35-55 and PLP 139-151 were synthesized at the Center for Neurologic Diseases, Brigham and Women's Hospital. 
Induction and clinical evaluation of EAE in APP-Tg mice. (B6XD2) $\mathrm{F}_{1}$ or (B6XSJL)F $F_{1}$ APP-Tg (WT or Ig $\left.\mu-n u l l\right)$ and non-Tg littermates were immunized with $100 \mu \mathrm{g}$ MOG 35-55, PLP 139-151, A $\beta$ 1-40, or BSA in CFA. Immediately thereafter and again 48 hours later, mice received an i.p. injection of $150 \mathrm{ng}$ PT in $0.2 \mathrm{ml}$ PBS. Beginning 7 days after immunization, animals were monitored for symptoms of EAE, which was scored as follows: 0 , no disease; 1 , tail paralysis; 2 , hind limb weakness; 3 , hind limb paralysis; 4, hind limb plus forelimb paralysis; 5 , moribund state.

Nasal vaccination. GA (25 $\mu \mathrm{g})$ was given on days $1,2,4$, and 5 the first week and then in weekly boosts for 6 weeks. IVX-908 ( $1 \mu \mathrm{g} /$ mouse) was given on days 1 and 5 the first week and then in weekly boosts for 6 weeks. BSA+IVX-908 (25 $\mu \mathrm{g}$ BSA plus $1 \mu \mathrm{g}$ IVX-908) was given on days 1 and 5 the first week, and $25 \mu \mathrm{g}$ of BSA alone was given on days 2 and 4 ; this was followed by 6 weekly boosts of the combination of BSA+IVX-908. GA+IVX908 (25 $\mu \mathrm{g}$ GA plus $1 \mu \mathrm{g}$ IVX-908) was given on days 1 and 5 the first week, and $25 \mu \mathrm{g}$ GA alone was given on days 2 and 4 . Mice received weekly boosts of GA+IVX-908 for 6 weeks (Figure 2) or beginning at age 5 months until age 14 months (Figure 3).

Amyloid quantification. Amyloid load was measured both as total A $\beta$ by using ELISA and as amyloid fibril using thioflavin $S$ staining. To quantify total $A \beta$, the right hemisphere of each mouse in each treatment group was extracted in 5.0 M guanidinium-chloride $(\mathrm{pH}$ 8) for 3 hours at room temperature. Dilutions were used to measure levels of $A \beta_{1-x}$ by sandwich ELISA (58). The ELISA assays performed on our samples were done with the same methodology and reagents used commercially in a Clinical Laboratory Improvement Amendments-approved laboratory to measure A $\beta$ levels in the CSF of humans (58). To measure $A \beta$ fibrils, the left hemisphere was fixed in $4 \%$ paraformaldehyde overnight, in $4.5 \%$ sucrose for 4 hours, then in $20 \%$ sucrose overnight at $4^{\circ} \mathrm{C}$. Brains were frozen in the presence of OCT and cut to $14-\mu \mathrm{m}$ longitudinal sections used for immunohistological staining and amyloid fibril quantification. For thioflavin $\mathrm{S}$ histochemical quantification, we studied 2 consecutive sections per animal and up to 10 animals per group; thus, multiple sections from the identical region were examined for each treatment group. Well-defined hippocampal regions (1.44 mm lateral to bregma) were selected for quantification of the amount of amyloid fibril in plaques using thioflavin $\mathrm{S}$ staining. To validate these findings, we stained an additional 4 sections of half the brain samples of the mice from each group. For consistency, the additional 4 sections were taken from the same brain regions in each animal, bregma 0.6 and bregma $1.8 \mathrm{~mm}$. We obtained identical results in the validation staining. As the thickness of each section was only $14 \mu \mathrm{m}$, there was a large distance between these 3 blocks, and therefore in each case, entirely different plaques were measured. The quantification was done in a blinded fashion using Imaging Research software from the NIH (NIH Image version 1.63; http://rhea.la.asu.edu/dm/software/nih_image). Images (magnification, $\times 20$ ) from these sections were collected from a 3-Compatible Camcorder/Digital color video camera (Carl Zeiss) and analyzed with appropriate software (Imaging Research; NIH). The amount of amyloid fibril or astrocytosis was expressed as a percentage per millimeter ${ }^{2}$ hippocampal region as measured by the software.

Immunohistology. Quantification was done for 2 consecutive sections (14 $\mu \mathrm{m})$ per animal, with 4-6 animals per group examined. The quantification was done in a blinded fashion using Imaging Research software from the NIH. The software allows one to mark each labeled cell in order to perform

quantification. H\&E staining was carried out to identify the morphology of cells counted. The analysis was done from the same region $(1.44 \mathrm{~mm}$ lateral to bregma) that was used for thioflavin $\mathrm{S}$ staining. The results are expressed as the mean of the labeled cells for each marker. Sections were evaluated in a blinded manner, and for control experiments, isotype-matched Abs were used as previously described (29) and H\&E staining used to identify the morphology of the cells counted. The staining was performed utilizing the following antibodies: $\mathrm{T}$ cells (CD3; 553057; BD), microglia/macrophages (CD11b $\mathrm{b}^{+}$ [MCA74G; Serotec]; CD68 [MCA1957; Serotec]; C-MFR [21080096; Cymbus Biotech]), IFN- $\gamma$ (559065; BD Biosciences - Pharmingen), IL-10 (559063; BD Biosciences - Pharmingen), TGF- $\beta$ (AB-20-PB; R\&D Systems), and CD68 (MCA1957; Serotec); rabbit anti-amyloid antibodies (R1282) were a gift of Dennis Selkoe (Brigham and Women's Hospital).

Neuropathology. To examine for neurotoxicity, the left hemisphere was fixed in $4 \%$ paraformaldehyde overnight, $4.5 \%$ sucrose for 4 hours, then $20 \%$ sucrose overnight at $4{ }^{\circ} \mathrm{C}$. Brains were frozen in the presence of OCT paraformaldehyde, cut to $14-\mu \mathrm{m}$ longitudinal sections, and used for immunohistological staining. We stained for 4 markers of neuronal stress and BBB integrity: GFAP (G9269; Sigma-Aldrich), SMI32 (Serotec), TUNEL (1 684 817; Roche Diagnostics Corp.), iNOS (AB5382; Chemicon International), and fibrinogen (A0080; DakoCytomation). Astrocytosis is expressed as a percentage per $\mathrm{mm}^{2}$ of the hippocampal region covered by astrocytes. Staining for iNOS, SMI32, and fibrinogen was performed as previously described (29). Staining for TUNEL was carried out according to manufacturer's (Roche Diagnostics Corp.) recommendations. H\&E staining was carried out to identify the morphology of cells counted. The staining was performed on 2 consecutive sections per animal and 4 animals per group in a blinded fashion using Imaging Research software from the NIH in an unbiased stereological approach. Staining was performed in the primary motor cortex of each group (1.44 mm lateral to bregma) is shown in Figure 9.

Statistical analysis. Data comparisons were carried out using 2-tailed Student's $t$ test when 2 groups were compared or 1-way ANOVA analysis when 3 or more groups were analyzed. $P$ values less than 0.05 were considered statistically significant; $r$ values were calculated using an Excel statistical program version 7 (Microsoft Corp.).

\section{Acknowledgments}

We wish to express our gratitude to Dennis Selkoe for helpful discussions and critical review of the manuscript, to Weiming Xia and Jennifer Strahle (Brigham and Women's Hospital) for performing the total $A \beta$ analysis, and to Sanja Petrovic for helping in immunohistological analysis. This work was supported by grant from the NIH (to H.L. Weiner) and a Human Frontier Science Program Fellowship (to D. Frenkel).

Received for publication September 2, 2004, and accepted in revised form June 7, 2005.

Address correspondence to: Howard L. Weiner, Center for Neurologic Diseases, Department of Neurology, Brigham and Women's Hospital, Harvard Medical School, 77 Avenue Louis Pasteur, Harvard Institute of Medicine 730, Boston, Massachusetts 02115, USA. Phone: (617) 525-5300; Fax: (617) 525-5252; E-mail: hweiner@rics.bwh.harvard.edu.

\footnotetext{
1. Hardy, J, and Selkoe, D.J. 2002. The amyloid hypothesis of Alzheimer's disease: progress and problems on the road to therapeutics [review]. Science. 297:353-356.

2. Hutton, M., and McGowan, E. 2004. Clearing tau pathology with abeta immunotherapy - reversible and irreversible stages revealed. Neuron.

43:293-294.

3. Busciglio, J., Lorenzo, A., Yeh, J., and Yankner, B.A. 1995. beta-amyloid fibrils induce tau phosphorylation and loss of microtubule binding. Neuron. 14:879-888.

4. Schenk, D., et al. 1999. Immunization with amyloid-beta attenuates Alzheimer-disease-like pathol-
}

ogy in the PDAPP mouse. Nature. 400:173-177.

5. Weiner, H.L., et al. 2000. Nasal administration of amyloid-beta peptide decreases cerebral amyloid burden in a mouse model of Alzheimer's disease. Ann. Neurol. 48:567-579.

6. Morgan, D., et al. 2000. A beta peptide vaccination prevents memory loss in an animal model of 
Alzheimer's disease. Nature. 408:982-985.

7. Janus, C., et al. 2000. A beta peptide immunization reduces behavioural impairment and plaques in a model of Alzheimer's disease. Nature. 408:979-982.

8. Dodart, J.C., et al. 2002. Immunization reverses memory deficits without reducing brain Abeta burden in Alzheimer's disease model. Nat. Neurosci. 5:452-457.

9. Bard, F., et al. 2000. Peripherally administered antibodies against amyloid beta-peptide enter the central nervous system and reduce pathology in a mouse model of Alzheimer disease. Nat. Med. 6:916-919.

10. DeMattos, R.B., et al. 2001. Peripheral anti-A beta antibody alters CNS and plasma A beta clearance and decreases brain A beta burden in a mouse model of Alzheimer's disease. Proc. Natl. Acad. Sci. U. S. A. 98:8850-8855.

11. Solomon, B., Koppel, R., Hanan, E., and Katzav, T. 1996. Monoclonal antibodies inhibit in vitro fibrillar aggregation of the Alzheimer beta-amyloid peptide. Proc. Natl. Acad. Sci. U. S. A. 93:452-455.

12. Solomon, B., Koppel, R., Frenkel, D., and HananAharon, E. 1997. Disaggregation of Alzheimer beta-amyloid by site-directed mAb. Proc. Natl. Acad. Sci. U. S. A. 94:4109-4112.

13. Morgan, D., and Gitter, B.D. 2004. Evidence supporting a role for anti-Abeta antibodies in the treatment of Alzheimer's disease. Neurobiol. Aging. 25:605-608

14. Wilcock, D.M., et al. 2003. Intracranially administered anti-Abeta antibodies reduce beta-amyloid deposition by mechanisms both independent of and associated with microglial activation. J. Neurosci. 23:3745-3751.

15. Wilcock, D.M., et al. 2004. Microglial activation facilitates Abeta plaque removal following intracranial anti-Abeta antibody administration. Neurobiol. Dis. 15:11-20.

16. Wilcock, D.M., et al. 2001. Number of Abeta inoculations in APP+PS1 transgenic mice influences antibody titers, microglial activation, and congophilic plaque levels. DNA Cell Biol. 20:731-736.

17. Frenkel, D., Balass, M., Katchalski-Katzir, E., and Solomon, B. 1999. High affinity binding of monoclonal antibodies to the sequential epitope EFRH of beta-amyloid peptide is essential for modulation of fibrillar aggregation. J. Neuroimmunol. 95:136-142.

18. Das, P., et al. 2003. Amyloid-beta immunization effectively reduces amyloid deposition in FcRgamma-/- knock-out mice. J. Neurosci. 23:8532-8538.

19. Orgogozo, J.M., et al. 2003. Subacute meningoencephalitis in a subset of patients with AD after Abeta42 immunization. Neurology. 61:46-54.

20. Nicoll, J.A., et al. 2003. Neuropathology of human Alzheimer disease after immunization with amyloidbeta peptide: a case report. Nat. Med. 9:448-452.

21. Hock, C., et al. 2003. Antibodies against beta-amyloid slow cognitive decline in Alzheimer's disease. Neuron. 38:547-554.

22. Fries, L.F., et al. 2001. Safety and immunogenicity of a proteosome-Shigella flexneri 2a lipopolysaccharide vaccine administered intranasally to healthy adults. Infect. Immun. 69:4545-4553.

23. Johnson, K.P., et al. 1995. Copolymer 1 reduces relapse rate and improves disability in relapsing- remitting multiple sclerosis: results of a phase III multicenter, double-blind placebo-controlled trial. The Copolymer 1 Multiple Sclerosis Study Group. Neurology. 45:1268-1276.

24. Mucke, L., et al. 2000. High-level neuronal expression of abeta 1-42 in wild-type human amyloid protein precursor transgenic mice: synaptotoxicity without plaque formation. J. Neurosci. 20:4050-4058.

25. Hsiao, K., et al. 1996. Correlative memory deficits, Abeta elevation, and amyloid plaques in transgenic mice. Science. 274:99-102.

26. Aharoni, R., Teitelbaum, D., Sela, M., and Arnon, R. 1997. Copolymer 1 induces $T$ cells of the $T$ helper type 2 that crossreact with myelin basic protein and suppress experimental autoimmune encephalomyelitis. Proc. Natl. Acad. Sci. U. S. A. 94:10821-10826.

27. Faria, A.M., and Weiner, H.L. 2005. Oral tolerance. Immunol. Rev. 206:232-259.

28. Maron, R., et al. 2002. Mucosal administration of heat shock protein- 65 decreases atherosclerosis and inflammation in aortic arch of low-density lipoprotein receptor-deficient mice. Circulation. 106:1708-1715.

29. Frenkel, D., et al. 2003. Nasal vaccination with myelin oligodendrocyte glycoprotein reduces stroke size by inducing IL-10-producing CD4+ T cells. J. Immunol. 171:6549-6555.

30. Plante, M., et al. 2001. Nasal immunization with subunit proteosome influenza vaccines induces serum HAI, mucosal IgA and protection against influenza challenge. Vaccine. 20:218-225.

31. Jones, T., et al. 2004. Protollin: a novel adjuvant for intranasal vaccines. Vaccine. 22:3691-3697.

32. Wyss-Coray, T., et al. 2002. Prominent neurodegeneration and increased plaque formation in complement-inhibited Alzheimer's mice. Proc. Natl. Acad. Sci. U. S. A. 99:10837-10842.

33. Buttini, M., et al. 2002. Modulation of Alzheimerlike synaptic and cholinergic deficits in transgenic mice by human apolipoprotein $\mathrm{E}$ depends on isoform, aging, and overexpression of amyloid beta peptides but not on plaque formation. J. Neurosci. 22:10539-10548.

34. Seabrook, T.J., et al. 2004. Species-specific immune response to immunization with human versus rodent A beta peptide. Neurobiol. Aging. 25:1141-1151.

35. Rogers, J., Strohmeyer, R., Kovelowski, C.J., and Li, R. 2002. Microglia and inflammatory mechanisms in the clearance of amyloid beta peptide. Glia. 40:260-269.

36. Kirk, J., Plumb, J., Mirakhur, M., and McQuaid, S. 2003. Tight junctional abnormality in multiple sclerosis white matter affects all calibres of vessel and is associated with blood-brain barrier leakage and active demyelination. J. Pathol. 201:319-327.

37. Kipnis, J., et al. 2003. Therapeutic vaccination for closed head injury. J. Neurotrauma. 20:559-569.

38. Kipnis, J., et al. 2000. T cell immunity to copolymer 1 confers neuroprotection on the damaged optic nerve: possible therapy for optic neuropathies. Proc. Natl. Acad. Sci. U. S. A. 97:7446-7451.

39. Angelov, D.N., et al. 2003. Therapeutic vaccine for acute and chronic motor neuron diseases: implications for amyotrophic lateral sclerosis. Proc. Natl. Acad. Sci. U. S. A. 100:4790-4795.
40. Benner, E.J., et al. 2004. Therapeutic immunization protects dopaminergic neurons in a mouse model of Parkinson's disease. Proc. Natl. Acad. Sci. U. S. A. 101:9435-9440.

41. D'Andrea, M.R., Cole, G.M., and Ard, M.D. 2004. The microglial phagocytic role with specific plaque types in the Alzheimer disease brain. Neurobiol. Aging. 25:675-683.

42. Mitrasinovic, O.M., and Murphy, G.M., Jr. 2003. Microglial overexpression of the M-CSF receptor augments phagocytosis of opsonized Abeta. Neurobiol. Aging. 24:807-815.

43. Webster, S.D., et al. 2000. Complement component $\mathrm{C} 1 \mathrm{q}$ modulates the phagocytosis of Abeta by microglia. Exp. Neurol. 161:127-138.

44. Bacskai, B.J., et al. 2002. Non-Fc-mediated mechanisms are involved in clearance of amyloid-beta in vivo by immunotherapy. J. Neurosci. 22:7873-7878.

45. Wyss-Coray, T., et al. 1997. Amyloidogenic role of cytokine TGF-beta 1 in transgenic mice and in Alzheimer's disease. Nature. 389:603-606.

46. Wyss-Coray, T., et al. 2001. TGF-beta1 promotes microglial amyloid-beta clearance and reduces plaque burden in transgenic mice. Nat. Med. 7:612-618.

47. DiCarlo, G., Wilcock, D., Henderson, D., Gordon, M., and Morgan, D. 2001. Intrahippocampal LPS injections reduce Abeta load in APP+PS1 transgenic mice. Neurobiol. Aging. 22:1007-1012.

48. Massari, P., et al. 2002. Cutting edge: immune stimulation by neisserial porins is toll-like receptor 2 and MyD88 dependent. J. Immunol. 168:1533-1537.

49. Kotilinek, L.A., et al. 2002. Reversible memory loss in a mouse transgenic model of Alzheimer's disease. J. Neurosci. 22:6331-6335.

50. McGeer, P.L., and McGeer, E. 2003. Is there a future for vaccination as a treatment for Alzheimer's disease? Neurobiol. Aging. 24:391-395.

51. Weiner, H.L., and Selkoe, D.J. 2002. Inflammation and therapeutic vaccination in CNS diseases. Nature. 420:879-884.

52. Gandy, S., and Walker, L. 2004. Toward modeling hemorrhagic and encephalitic complications of Alzheimer amyloid-beta vaccination in nonhuman primates. Curr. Opin. Immunol. 16:607-615.

53. Monsonego, A., et al. 2003. Increased T cell reactivity to amyloid $\beta$ protein in older humans and patients with Alzheimer disease. J. Clin. Invest. 112:415-422. doi:10.1172/JCI200318104.

54. Monsonego, A., and Weiner, H.L. 2003. Immunotherapeutic approaches to Alzheimer's disease. Science. 302:834-838.

55. Akiyama, H., and McGeer, P.L. 2004. Specificity of mechanisms for plaque removal after A beta immunotherapy for Alzheimer disease. Nat. Med. 10:117-118; author reply 10:118-119.

56. Streit, W.J. 2004. Microglia and Alzheimer's disease pathogenesis. J. Neurosci. Res. 77:1-8.

57. Kuo, Y.M., et al. 2001. Comparative analysis of amyloid-beta chemical structure and amyloid plaque morphology of transgenic mouse and Alzheimer's disease brains. J. Biol. Chem. 276:12991-12998.

58. Johnson-Wood, K., et al. 1997. Amyloid precursor protein processing and A beta 42 deposition in a transgenic mouse model of Alzheimer disease. Proc. Natl. Acad. Sci. U. S. A. 94:1550-1555. 